\title{
Influence of rotor solidity on trailing edge noise from wind turbine blades
}

\author{
Vasishta Bhargava Nukala ${ }^{1^{*}}$ iD and Satya Prasad Maddula ${ }^{2}$
}

\footnotetext{
* Correspondence: vasishtab@gmail. com

${ }^{1}$ Department of Mechanical Engineering, Sreyas Institute of Engineering and Technology, Nagole, Hyderabad, Telangana, India Full list of author information is available at the end of the article
}

\begin{abstract}
Noise prediction from streamlined bodies such as wind turbine blades can be predicted accurately using CFD computations that use spatio-temporal turbulence models at the expense of high computational power. In this work, empirical methods proposed from BPM, Grosveld and Lowson are used to compute numerically to analyse the influence of rotor solidity factor on broadband trailing edge noise from a $2 \mathrm{MW}$ horizontal axis wind turbine with a blade length of $37 \mathrm{~m}$. Inputs to acoustic solver are the velocity vector field and boundary layer data which are obtained using blade element momentum and X-Foil. The outputs from acoustic solver are directivity and far field sound pressure on a receiver located at distance of $120 \mathrm{~m}$ from tower base. The results have shown that for a wind speed of $10 \mathrm{~m} / \mathrm{s}$ measured at $10 \mathrm{~m}$ above ground, sound power level was found to increase between mid-bands to high frequencies for all three methods. Rotor solidity effect was illustrated at constant rotational speed of 17 RPM and receiver height of $0.5 \mathrm{~m}$ located in downwind position. A minimum difference of $1.5 \mathrm{dBA}$ was found at $f \sim$ $100 \mathrm{~Hz}$ for Lowson method and maximum of $\sim 2.8 \mathrm{dBA}$ at $1 \mathrm{kHz}$ between two and three blade rotor. For BPM and Grosveld methods however, the sound levels were $5 \mathrm{dBA}$ lower for two blade rotor than three blade rotor between $\mathrm{f} \sim 100 \mathrm{~Hz}$ and $\mathrm{f} \sim 1$ $\mathrm{kHz}$. The study also demonstrated that as number of blades increase by integral multiples, the effect on noise radiation from trailing edge of blades increase by 2 $5 \mathrm{dBA}$ due to amplitude modulation.
\end{abstract}

Keywords: Sound power, Boundary layer, Wind turbine, Blade, Trailing edge

\section{Introduction}

In the past decade, size of wind turbines has grown considerably faster from a few kilo-watt to multi megawatt type in order to produce power for various needs of the society [1]. Installations of turbine sizes of order of $5 \mathrm{MW}$ are becoming increasingly popular in developed countries like UK, Germany, US and other European countries. With increase in turbine size, blade lengths of $68 \mathrm{~m}$ are obviously required in order to produce higher power. As length of blades grows, the tip speed of the machine also increases dramatically and leads to production of noise from rotating blades. Noise from operating wind turbines contributes to annoyance, sleep disturbance and sometimes speech interference to inhabitants living near them [1-4]. Several noise regulations applicable for different types of environments are prescribed by national and international

(c) The Author(s). 2020 Open Access This article is licensed under a Creative Commons Attribution 4.0 International License, which permits use, sharing, adaptation, distribution and reproduction in any medium or format, as long as you give appropriate credit to the original author(s) and the source, provide a link to the Creative Commons licence, and indicate if changes were made. The images or other third party material in this article are included in the article's Creative Commons licence, unless indicated otherwise in a credit line to the material. If material is not included in the article's Creative Commons licence and your intended use is not permitted by statutory regulation or exceeds the permitted use, you will need to obtain permission directly from the copyright holder. To view a copy of this licence, visit http://creativecommons.org/licenses/by/4.0/. 
authorities in order to put threshold levels for noise emitted during day or night times [1]. Community or occupational noise requirements are mentioned according to national or regional standards that provide useful findings about how perception of noise is subjected to indoor or outdoor conditions and time duration of measurement of noise levels. In addition, noise regulation for onshore wind turbines is given by IEC 61400-11, ISO 9613-2 standards, and based on wind speed that is measured at $10 \mathrm{~m}$ above ground to determine the equivalent continuous sound pressure level or apparent sound power level. It also recommends validation procedures to conduct microphone measurements and standards pertaining to acceptable acoustic data quality. Although flow induced noise in free field occurs due to small scale pressure or density fluctuations, noise from wind turbine blades is an aspect related to aerofoil self-noise mechanism [5]. Many empirical and experimental studies on aerofoil self-noise mechanisms have been conducted, which provided useful results that are able to predict the noise from trailing edge surfaces in turbulent wind field [6]. In the past, several researchers who conducted potential studies related to wind turbine noise have demonstrated that main contribution from wind turbine noise occurs from trailing edge of blade section and predominantly broadband in nature [2, 4, 7-10]. Further, empirical methods have proven that major noise mechanisms occur due to the interaction between turbulent boundary layer and the lifting surfaces such as aerofoils of a rotating blade. Rotating blades as found in a helicopter are similar to that of wind turbine but differ in their orientation, for which trailing edge noise radiation is caused due to unsteady aerodynamic loading when turbulent ingestion of air flows over outboard trailing edge sections of rotor than inboard sections $[2,5]$. It has been found that for low Mach number flows efficient sound generation is produced when the turbulent boundary layer undergoes edge scattering at the trailing edge surface $[2-4,7,8,11-13]$. The intensity of such noise radiation depends on the surface treatment as well as the geometry of trailing edge such as trailing edge thickness, serrations or porosity $[6-9,14,15]$. In addition, the number of blades in a wind turbine often has remarkable effect on sound generation process. Even though there are other class of methods that can predict sound power levels (SPL) using rotor diameter, thrust coefficient, blade tip speed and nominal power of machine, they fail to provide comprehensive understanding of the noise mechanisms from multiple sources. According to the authors' knowledge, there has been no computational study performed previously which analysed the effect of number of blades on noise levels from a horizontal axis wind turbine. This paper attempts to analyse such effect and aims to predict the 1/3rd octave band sound power level from a $2 \mathrm{MW}$ horizontal axis wind turbine with a blade length of $37 \mathrm{~m}$ using three different trailing edge noise models, viz. BPM (Brookes, Pope and Marcolini), Lowson and Grosveld. Computer simulations are conducted to verify the impact of number of blades in a wind turbine on sound power level. According to IEC 61400-11 standard, the worst case microphone position is usually downwind and recommended distance equivalent to hub height plus the half rotor diameter has been implemented for assessing the intensity of sound level $[4,7-9,11,16]$.

\section{Trailing edge noise prediction methods}

\subsection{BPM (Brookes, Pope and Marcolini)}

Brooks et al. (1989) derived this model using data from wind tunnel experiments with NACA0012 symmetric aerofoil with varying chord lengths up to $0.5 \mathrm{~m}$ in an anechoic 
chamber. Aerofoil is assumed as half-infinite flat plate with respect to far field observer. The turbulent boundary layer trailing edge noise (TBL-TEN) occurs from both suction and pressure sides of aerofoil and is considered as common source of noise from wind turbine blade. The turbulent boundary layer thickness, $\delta$, displacement thickness, $\delta$, local Mach number (M), length of blade segment (L), as well as the distance between the observer and source $\left(\mathrm{r}_{\mathrm{e}}\right)$ are important parameters to predict the acoustic field from 2D lifting surfaces [5, 6]. Eq. 1 and Eq. 2 are used to calculate the sound pressure involving spectral functions, while Eq. 3 is used for angle dependent noise source, which is based on flow separation over aerofoil caused at moderate to high angle of attack (AOA) $[4,6,9,11]$. Noise radiation occurs as result of interaction of turbulent boundary layer with trailing edge surface of an aerofoil for an incident hydrodynamic pressure field. To a large extent, this noise is radiated normal to surface of aerofoil and extends upstream along chord length in form of a cardioid. The fluctuating pressure field affects the incoming wind flow and causes shear stress in fluid, which leads to local pressure rise higher than atmospheric pressure. The sound pressure levels are hence obtained by adding all the components logarithmically for each blade section and given by Eq. 4

$$
\begin{aligned}
& \mathrm{SPL}_{\mathrm{p}}=10 . \log 10\left[\frac{\delta_{\mathrm{p}}^{*} \mathrm{M}^{5} \mathrm{~L} \overline{\mathrm{D}_{\mathrm{h}}}}{\mathrm{r}_{\mathrm{e}}^{2}}\right]+\mathrm{A}\left[\frac{\mathrm{St}_{\mathrm{p}}}{\mathrm{St_{1 }}}\right]+[\mathrm{K} 1-3]+\Delta \mathrm{K} 1 \\
& \mathrm{SPL}_{\mathrm{s}}=10 \cdot \log 10\left[\frac{\delta_{\mathrm{s}}^{*} \mathrm{M}^{5} \mathrm{~L} \overline{\mathrm{D}_{\mathrm{h}}}}{\mathrm{r}_{\mathrm{e}}^{2}}\right]+\mathrm{A}\left[\frac{\mathrm{St}_{\mathrm{s}}}{\mathrm{St}_{1}}\right]+[\mathrm{K} 1-3] \\
& \mathrm{SPL}_{\alpha}=10 \cdot \log 10\left[\frac{\delta_{\mathrm{s}}^{*} \mathrm{M}^{5} \mathrm{~L} \overline{D_{\mathrm{h}}}}{\mathrm{r}_{\mathrm{e}}^{2}}\right]+\mathrm{B}\left[\frac{\mathrm{St}_{\mathrm{s}}}{\mathrm{St}_{2}}\right]+\mathrm{K} 2 \\
& \mathrm{SPL}_{\text {Total }}=\sum 10 \cdot \log 10\left[\sum_{n=1}^{x} 10^{\frac{\mathrm{SP} \mathrm{L}_{\mathrm{x}}}{10}}\right]
\end{aligned}
$$

Where, $x$ refers to the type of source component. The Strouhal number (St) is used for describing oscillating flows, which involve center frequency as well as characteristic dimension of source. For flow over aerofoil, it is calculated using pressure and suction side displacement thickness, given by Eq. 5

$$
\mathrm{St}=\chi\left(\mathrm{f}, \delta_{\mathrm{k}}^{*}, \mathrm{U}, \mathrm{M}\right)
$$

Where $\mathrm{k}$ refers to the suction and pressure sides of aerofoil, $\delta^{*}$ is the boundary layer displacement thickness, $\mathrm{f}$ is $1 / 3 \mathrm{rd}$ octave center frequency. It can be noted that $\mathrm{St}_{1}$ is related to oscillating flow over aerofoil and along downstream of trailing edge. It varies with free stream velocity $(\mathrm{U})$ and Mach number $(\mathrm{M})$, while $\mathrm{St}_{2}$ is related to separation noise in spectra given in [2,9]. These parameters are set between 0.01 and 10 for low Mach number flows and vary along span direction. The Reynolds number expresses the relation between inertial and viscous forces in flow, measured along the chord direction of blade, given by Eq. 6. This parameter is function of pressure side displacement thickness and also chord length of aerofoil for calculating level adjustment function, $\Delta \mathrm{K} 1$, and amplitude functions, $\mathrm{K} 1$ and $\mathrm{K} 2$ respectively. For wind turbines, the blade experiences moderate to high Reynolds number (Re) of order, Re $-3.5 \times 10^{6}$ to $1.2 \times 10^{7}$ flows and vary along the blade span. This type of source uses high and low frequency directivity functions, given by Eq. 7 


$$
\begin{aligned}
& \operatorname{Re}=\psi\left(\mathrm{c}, \vartheta, \mathrm{U}, \delta_{\mathrm{k}}^{*}\right) \\
& \mathrm{D}_{\mathrm{h}}(\theta, \varnothing)=\frac{2 \sin ^{2}\left(\frac{1}{2} \theta\right) \sin ^{2}(\varnothing)}{(1+\mathrm{M} \cos \theta) \cdot\left(1+\left(\mathrm{M}-\mathrm{M}_{\mathrm{c}}\right) \cos \theta\right)^{2}} ; \mathrm{D}_{\mathrm{L}}(\theta, \varnothing)=\frac{\sin ^{2}(\theta) \sin ^{2}(\varnothing)}{(1+\mathrm{M} \cos \theta)^{4}}
\end{aligned}
$$

The boundary layer thickness $(\delta)$ and displacement thickness $\left(\delta^{*}\right)$ are calculated as function of the chord length of aerofoil, c, and angle of attack (AOA) for both pressure and suction sides of aerofoil, as given in [6]. For all components of this source, the acoustic pressure produced near trailing edge varies as fifth power of Mach number dependence or $\mathrm{M}^{5}$ and exhibits broadband characteristics. Further, for low Mach number flows, $\mathrm{M} \sim 0.2$, noise radiated from pressure and suction sides of aerofoil depends upon the spectral functions $\mathrm{A}$ and $\mathrm{B}$, which are correlated with the aerodynamic and boundary layer properties $[2,4,6]$. The spectral function $\mathrm{A}$ is related to turbulent boundary layer-trailing edge noise and function $\mathrm{B}$ with flow separation noise and contributes to low frequency noise. For non-compact sources and attached flows, high frequency directivity function $\left(D_{h}\right)$ is used and given by $\sin ^{2}\left(\frac{\theta}{2}\right)$. The combined Doppler shift and convective amplification terms use $(1+M \cos \theta)\left[1+\left(M-M_{c} \cos \theta\right)\right]^{2}$ to show a cardioid pattern of sound field near trailing edge, where $M_{c}$ is the convective Mach number. For stalled or fully separated flow on blade, the trailing edge noise source reduces to complex dipole pattern and becomes a function of $\mathrm{M}^{6}$. Therefore, for such case, angles of attack usually exceed $12.5^{\circ}$, for which low frequency directivity, $D_{L}$ is also used. The directivity angles, $\theta$ and $\varnothing$, are aligned in the azimuth and polar directions with respect to rotor plane and shown by coordinate reference system in $[2,4,6]$.

\subsection{Grosveld method}

In this model, noise is produced due to turbulent boundary layer attached to trailing edge surface of an aerofoil. It is similar to BPM model and based on scaling law prediction for trailing edge noise spectrum [2]. Since a wind turbine blade is tapered and twisted, the individual blade segments of length (l), encounter different local free stream velocities and experience unsteady blade lift and drag forces. However, this model assumes linearly tapered rotor and ignores twist, hence does account for corrections in the angle of attack over individual blade segments as in the case of BPM. For uniform 2D lifting flows, the trailing edge noise for an isolated aerofoil can be approached with Eq. 8 [2, 17].

$$
\mathrm{SPL}_{\text {total }}=10 \cdot \log 10\left[\frac{\mathrm{B} \delta \mathrm{U}^{5} \mathrm{LD}_{\mathrm{h}}}{\mathrm{r}_{\mathrm{e}}^{2}} \cdot \mathrm{KK}_{2}\right]+\mathrm{C}
$$

where $K_{2}$ is the frequency dependent scaling function, given by Eq. 9

$$
\mathrm{KK} 2(\mathrm{f})=10 . \log 10\left[\left\{\left(\frac{\mathrm{St}^{\prime}}{\mathrm{St}_{\max }}\right)^{4}\right\}\left[\left(\frac{\mathrm{St}^{\prime}}{\mathrm{St}_{\max }}\right)^{1.5}+0.5\right]^{-4}\right]
$$

where: $\mathrm{St}_{\max }$ is the peak Strouhal number set to $\sim 0.1$; and $\mathrm{St}^{\prime}$ is the Strouhal number as function of boundary layer thickness $-\delta$; $B$ is the number of blades; $U$ is the free stream velocity scaled to $\mathrm{U}^{5}$, Empirical constant $\mathrm{C}-5.44 \mathrm{~dB}$. 
Grosveld model uses the high frequency directivity function $\left(D_{h}\right)$ proposed by Fink [18], which is similar to Eq. 7. For turbulent flows, the thickness and displacement thickness of turbulent boundary layer for aerofoil are given by the empirical curve fitting function dependent on chord length (c) of aerofoil and angle of attack (AOA) and given by Eq. 23 and Eq. 33 in [2]. It must be noted that no blades and geometric properties determine the turbine rotor solidity. Hence this model also considers the rotor solidity factor in order to estimate the sound pressure level from a turbine. The Doppler shift and convective amplification term as discussed in BPM model is set equal to 0.8 times the Mach number to include the effects of dipole radiation of sound along the blade chord $[2,7,8]$. The overall $1 / 3$ rd octave band far field sound pressure level is obtained by logarithmic integration of individual contributions of blade elements for each blade.

\subsection{Lowson method}

In this model, the far field sound pressure level is predicted based on empirical equations similar to BPM method; however, the directional nature of sound is ignored [6, 17]. Sound pressure calculation involves the spectral function $G_{6}$, which depends on the Strouhal number, Mach number, boundary layer thickness, distance between source and receiver, as well as empirical constant. The empirical constant takes into account the turbulent wind field behavior and is evaluated using mathematical gamma function. In addition frequency dependent scaling factors are used in order to determine the sound pressure level and given by Eq. 10 and Eq. 11

$$
\begin{aligned}
& \mathrm{SPL}_{\text {total }}=10 \cdot \log 10\left[\frac{\delta \mathrm{M}^{5} \mathrm{~L}}{\mathrm{r}_{\mathrm{e}}^{2}} \cdot \mathrm{G}_{6}(\mathrm{f})\right]+128.5 \\
& G_{6}(\mathrm{f})=\frac{4\left(\frac{\mathrm{f}}{\mathrm{f}_{\text {max }}}\right)}{\left[\left(\frac{\mathrm{f}}{\mathrm{f}_{\text {max }}}\right)^{2.5}+1\right]^{2}}
\end{aligned}
$$

where: $f_{\max }$ is peak frequency and dependent on free stream Mach number $M$ and boundary layer thickness $\delta$. The boundary layer thickness is also approximated according to the Eq. 23 and Eq. 33 given in [2]. L-span segment length $\left(r_{e}\right)$ is the distance between the source and receiver, in $\mathrm{m}$.

It is known that acoustic fluctuations are significantly smaller compared to aerodynamic flow variables, and classical acoustic analogy as proposed by Lighthill demonstrates that source terms are function of aerodynamic field variables $[19,20]$. This analogy is based on density gradient which utilises perturbation component of density or pressure as fundamental flow field quantity. Direct simulation of this analogy requires high computational power for high Reynold number flows. The drawback with this approach is that the attenuation effects due to reflection and refraction are not included in the source term represented by Lighthill's stress tensor given by Eq. 1 in [21]. Turbulent source modelling of Lighthill's stress tensor is represented by self-noise term which is product of perturbation velocity components $u_{i} u_{j}$, while the shear noise term is represented by product of mean value of flow velocity and perturbation velocity $\mathrm{Uu}_{\mathrm{i}}$. The entropy fluctuations and viscous stresses are however included into source term, which means fluid outside the source region is assumed ideal and therefore sound field 
remains spatially invariant. Further, it is known that attenuation affects due to refraction on the acoustic pressures measured in upwind, downwind and cross wind directions are possible but for all three methods implemented in current study, the attenuation factors due to atmospheric refraction are not taken into account [10].

\subsection{Computational set up for noise prediction method}

Figure 1 shows the data driven approach implemented for the noise prediction methods described in sections 2.1 to 2.3. The algorithm for blade element momentum (BEM) and acoustic solver has been developed in MATLAB 2019 environment. The BEM algorithm utilizes the affine transformation techniques to describe the point to point correlation of velocity vector on blade during one rotation [3]. Aerofoils selected for approximating blade geometry are NACA 0012, NACA 6320 and NACA632xx and the look up table data for those aerofoils are used as input for deriving the relative velocity field over blade surface. The boundary layer data is obtained for selected aerofoils up to $25^{\circ}$ angle of attack using X-Foil. The program for $\mathrm{X}$ foil is obtained online from [22]. The results of X-Foil program are boundary layer data for the aerofoils, viz. boundary layer thickness and displacement thickness which are used as input to acoustic solver

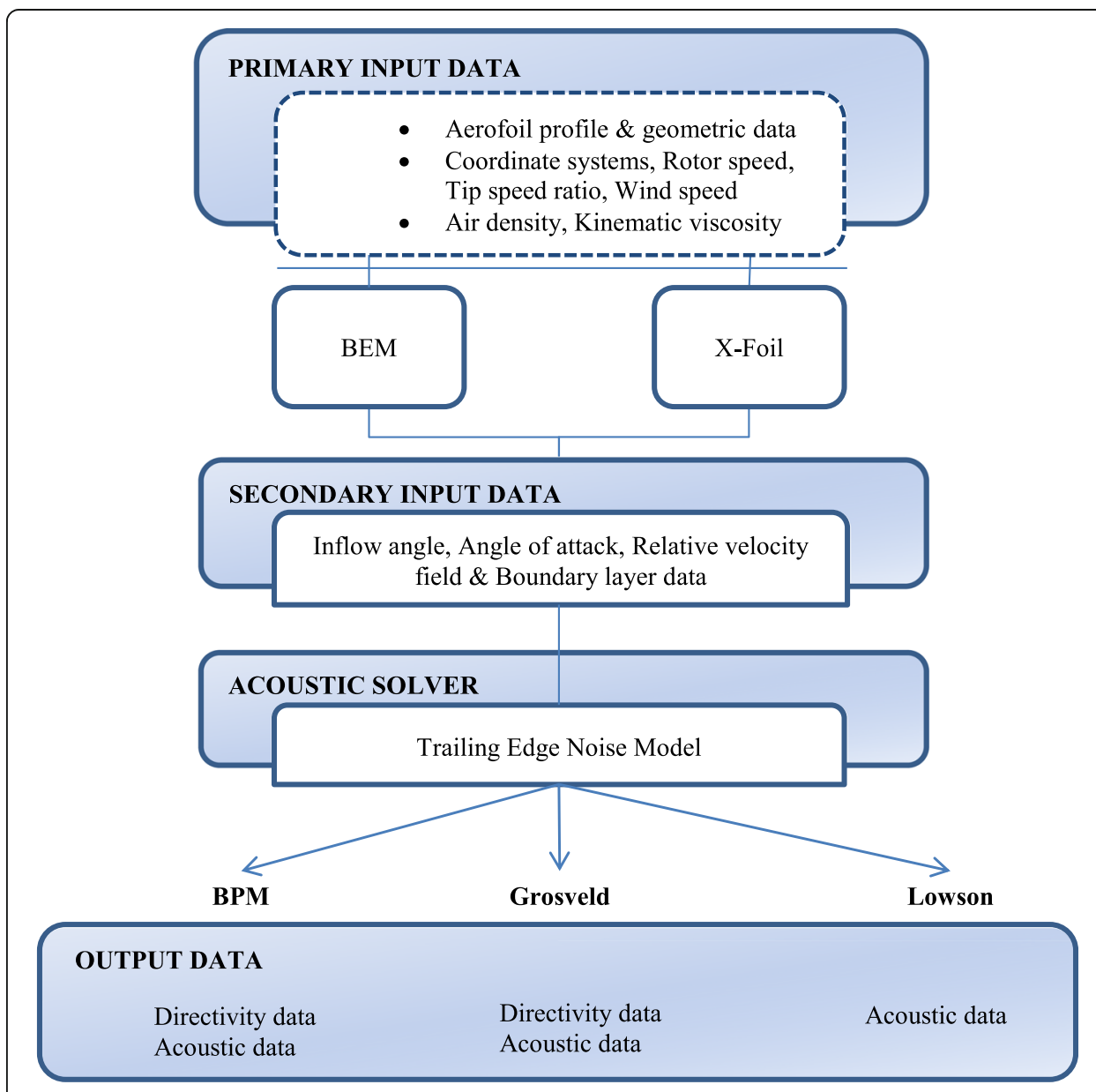

Fig. 1 Block diagram of computational setup of noise prediction method 
and hence allows to reduce the computation time in the acoustic simulation process. For investigating rotor solidity effect, the rotational speed of machine is kept constant at 17 RPM, other things being same, i.e. the blade geometric properties are kept constant both for three and two blade rotor. Further, for both cases the source height, receiver distance and position are also same. Figure 2 (a) shows the geometric properties of $37 \mathrm{~m}$ blade. The maximum chord length of blade is $3.22 \mathrm{~m}$ while the twist angle is $13^{\circ}$. The blade pitch angle is set to $\sim 4^{\circ}$. Fig. 2(b) illustrates the 3D model of wind turbine blade developed using NuMAD software (https:/energy.sandia.gov/energy/renewable-energy/wind-power/rotor-innovation/numerical-manufacturing-and-design-toolnumad/). It can be seen that outputs from Grosveld and BPM models produce both directivity and acoustic data while Lowson model produces only acoustic data as this method ignores the directivity. It must be noted that acoustic data is obtained after considering the acoustic pressure data over blade azimuth direction as well as number of blades for rotor in turbine model. Figure 3 shows the placement of microphone position around the turbine relative to the direction of prevailing wind. It also depicts the microphone distance equivalent to sum of source height $(\mathrm{HH})$ and half the rotor diameter from the tower centre. Figure 4(a) illustrates the rotor solidity from a wind turbine rotor with three blades as seen from upwind direction. Figure 4(b) depicts the rotor solidity for two blades at a constant hub height.

Further, from Fig. 3 it can be seen that $\mathrm{R}$ is the effective or slant distance between the hub centre (source height) to the microphone placed on ground. According to IEC 61400-11 standard, the recommended distance for placing the microphone must be equivalent to $\mathrm{HH}+\mathrm{D} / 2$, where $\mathrm{HH}$ is the hub height and $\mathrm{D}$ - rotor diameter, in $\mathrm{m}$. The microphone is located in downwind position relative to turbine rotor which accounts for the sound wave amplification and is considered as the worst case position. Therefore, the equivalent continuous A -weighted sound power level, $\mathrm{L}_{\mathrm{wA}}$ can be derived using the $1 / 3$ rd octave band equivalent continuous sound pressure. $\mathrm{L}_{\mathrm{Aeq}}$ and geometric spreading factor account for acoustic wave propagation within source region. In addition, the total attenuation factors account up to 6dBA in environment [16]. It is given by Eq. 12

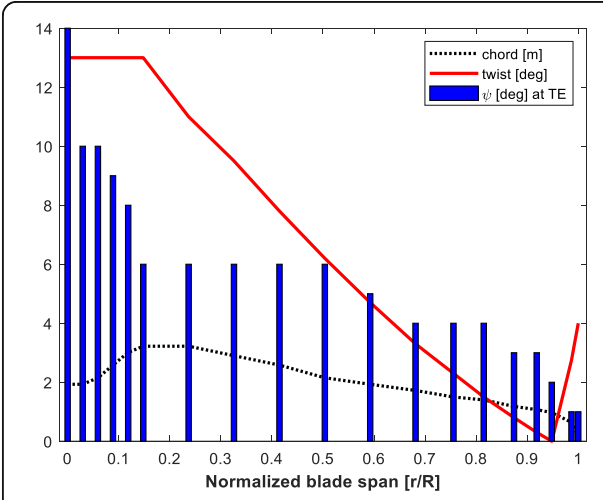

(a)

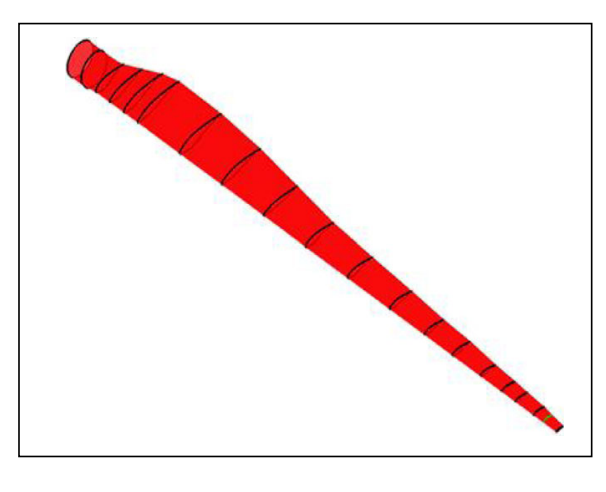

(b)

Fig. 2 a Geometric properties of $37 \mathrm{~m}$ blade length used for computational study (b) 3D model of wind turbine blade developed using NuMAD software (https://energy.sandia.gov/energy/renewable-energy/wind-power/rotor-innovation/numericalmanufacturing-and-design-tool-numad/) 


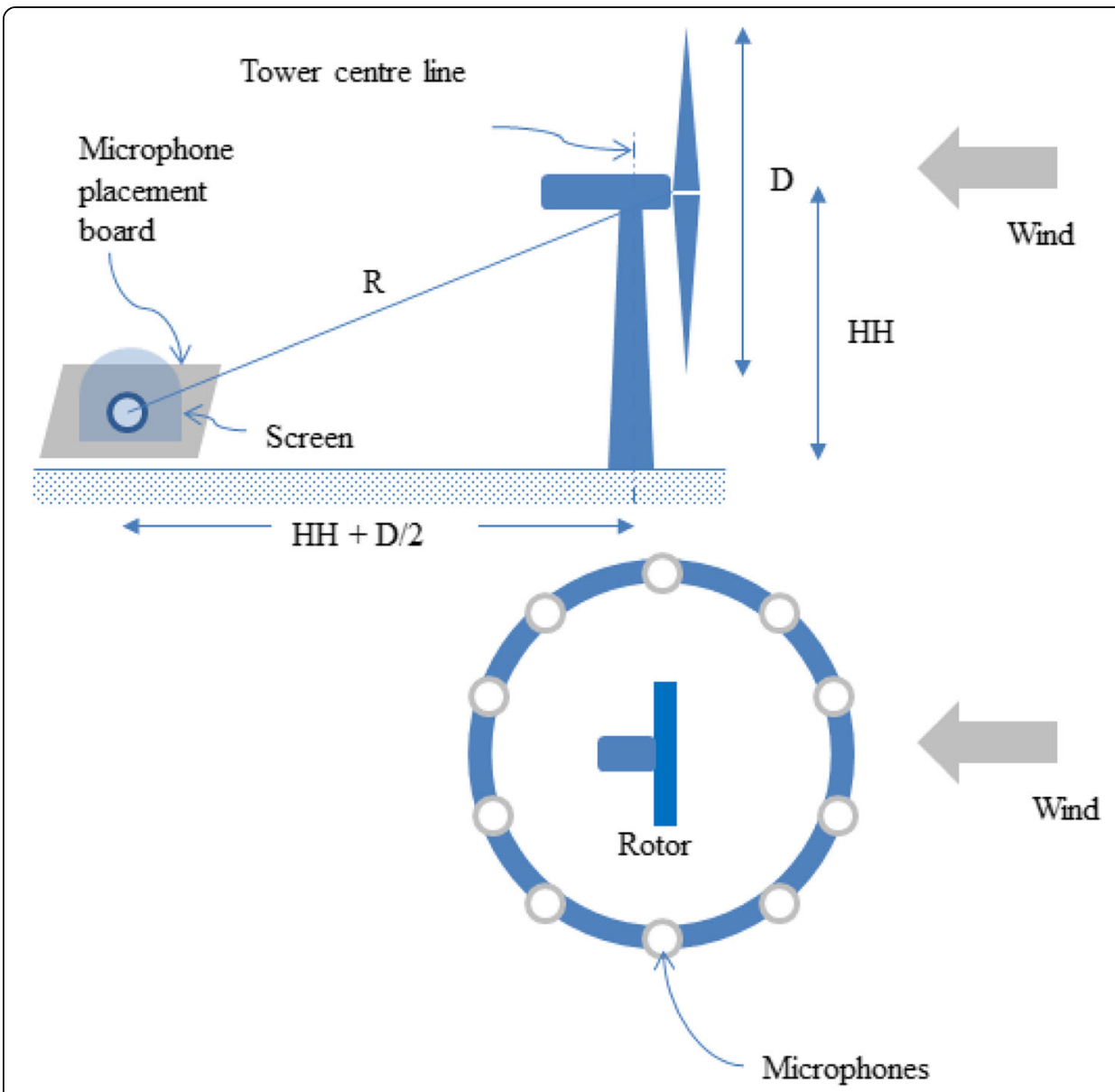

Fig. 3 Illustration of microphone position surrounding the source located in centre as well as the microphone measurement distances and position according to IEC 61400-11 standards with respect to source

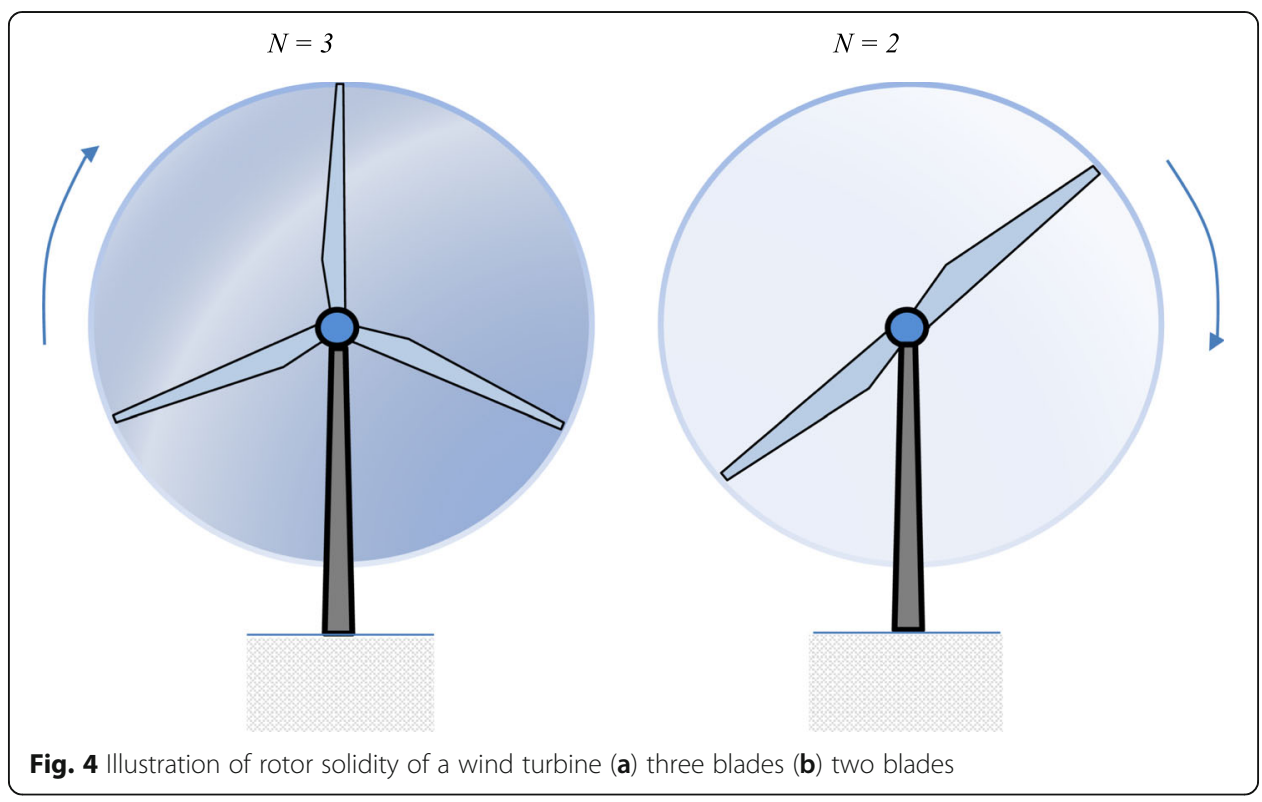




$$
\mathrm{L}_{\mathrm{wA}}=\mathrm{L}_{\text {Aeq }}+10 \log 10\left[\frac{4 \pi \mathrm{R}^{2}}{\mathrm{~S}_{0}}\right]-6
$$

$\mathrm{S}_{0}$ is the reference area, $1 \mathrm{~m}^{2} ; \mathrm{L}_{\text {Aeq }}$ is the far field equivalent continuous A-weighted sound pressure level evaluated using the noise prediction methods discussed in sections 2.1 to 2.3 .

It must be noted that blade solidity parameter is the ratio of blade plan form area to the swept area of rotor, and for a wind turbine blade, it can be expressed in terms of local chord length, c, and blade radius, r, given by Eq. 13

$$
\sigma_{\mathrm{b}}=\frac{\mathrm{Nc}}{2 \pi \mathrm{r}}
$$

Where, $\mathrm{N}$ - is number of blades in rotor. Towards the outboard section of blade, the chord length and surface area reduce gradually and hence local solidity, while for inboard region of blade where chord length is found maximum, the local solidity increases.

\subsubsection{Implementation of blade element momentum (BEM) algorithm}

Figure 5 shows the flow chart for BEM implementation in the computational set up illustrated in the beginning of section 2.4. As mentioned earlier in the section, velocity field outputs from BEM are coupled to the boundary layer data obtained for each of models in order to evaluate sound pressure level.

Following are the steps that are solved iteratively in the BEM approach.

1. Initialize $a$ and $a^{\prime}$ with starting values as zeros

2. Evaluate the inflow angle,

3. Compute the local angle of attack, $\alpha$

4. Read aerodynamic force coefficient data vs angle of attack, $C_{l}(\alpha)$ and $C_{d}(\alpha)$

5. Compute normal $\left(C_{n}\right)$ and tangential $\left(C_{t}\right)$ force coefficients

6. Calculate axial and tangential induction factors, $a$ and $a$ '

7. Specify tolerance criteria for $a$ and $a^{\prime}$ as convergence limit; else go to step 2

8. Calculate the tip correction factors, Prandtl model

9. Compute the local forces on the blade till the stall angle of attack (typically range for $\alpha$ values are from $14^{\circ}$ up to $30^{\circ}$ )

It must be noted that aerodynamic force coefficients $C_{l}$ and $C_{d}$ for the present study consider 2D profile lookup table data. This data is interpolated for each blade station during each revolution of blade to estimate lift and drag coefficients necessary for evaluating normal and tangential load coefficients. Linear interpolation has been done due to its simple procedure. The local loads between any radius, $r_{i}$ and $r_{i+1}$ are evaluated using interp 1 function in MATLAB. However the mathematical form for evaluating linear interpolation of a given parameter is given by Eq. 6.25 to Eq.6.27 given in [8]. The individual expression for differential torque over an infinitesimal part of blade of length $d r$ is given by Eq. 6.28 in [8]. It shows that total main shaft torque or the tangential load varies linearly between any two points, $r_{i}$ and $r_{i+1}$ along the blade span length. Further, for simulation of the acoustic field, flow along the spanwise direction is assumed to be quasi-uniform and incompressible between individual span segments. This 


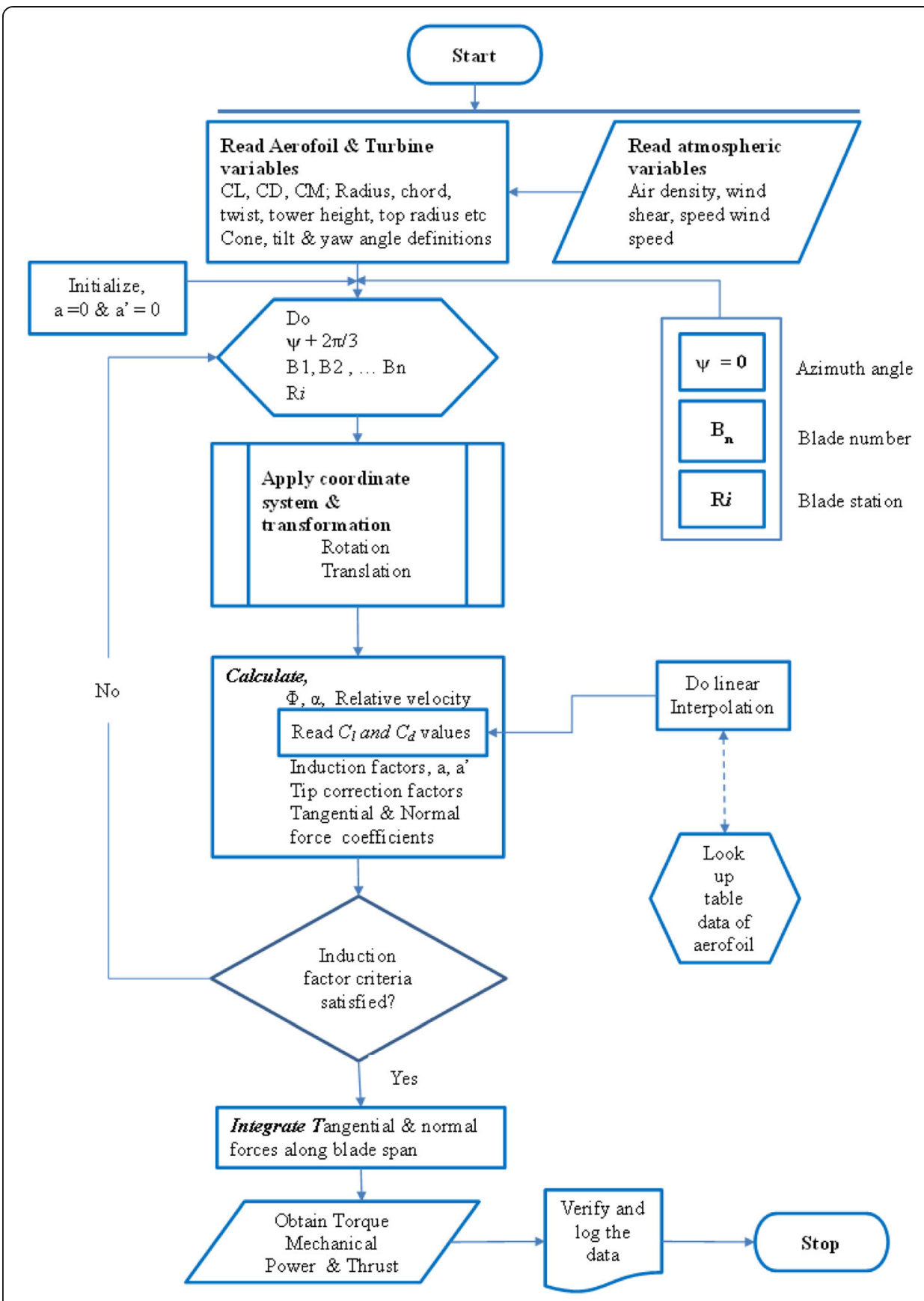

Fig. 5 Flow chart for implementing blade element momentum (BEM) algorithm

also means there is partial dependency of aerodynamic flow field parameters such as lift and drag coefficients of profiles for individual blades so that the total aerodynamic load is equal to sum of all contributions of one blade multiplied by number of blades in rotor.

\subsubsection{Evaluation of boundary layer parameters}

According to BPM model [6], the boundary layer parameters for the aerofoil surfaces are evaluated as function of chord length of aerofoil and angle of attack. The boundary 
layer thickness parameters at the trailing edge are obtained from curve fitting expressions for the experimental data for NACA symmetric aerofoil at zero and non-zero angle of attack conditions. These are determined for both the pressure side and suction side when the boundary layer is attached, separated at trailing edge or separated at enough distance upstream of chord to produce stall $[4,6]$. The boundary layers can be tripped if the flow separation over the surface of aerofoil is made to occur by introducing grit or rime or by placing tapes along span for a given chord location. Boundary layer thicknesses for tripped condition transform the flow into turbulent state much earlier than natural flow transitions, while for un-tripped cases it remains undisturbed. For zero angle of attack conditions, the boundary layer thickness, displacement thickness and momentum thickness are given by Eq. 14 to Eq. 16

$$
\begin{aligned}
& \frac{\delta_{0}}{\mathrm{c}}=10^{\left[1.657-0.9045 \log \mathrm{R}_{\mathrm{c}}+0.0596\left(\log \mathrm{R}_{\mathrm{c}}\right)^{2}\right]} \\
& \frac{\delta_{0}^{*}}{\mathrm{c}}=10^{\left[3.0187-1.5387 \log R_{\mathrm{c}}+0.1059\left(\log \mathrm{R}_{\mathrm{c}}\right)^{2}\right]} \\
& \frac{\theta_{0}}{\mathrm{c}}=10^{\left[0.2021-0.7079 \log \mathrm{R}_{\mathrm{c}}+0.0404\left(\log \mathrm{R}_{\mathrm{c}}\right)^{2}\right]}
\end{aligned}
$$

For non-zero angle of attack on aerofoil, the boundary layer thickness, displacement thickness and momentum thickness of the pressure side of aerofoil are same for tripped and untripped conditions and a function of Reynolds number.

$$
\begin{aligned}
& \frac{\delta_{\mathrm{p}}}{\delta_{0}}=10^{\left[-0.04175 \alpha+0.00106 \alpha^{2}\right]} \\
& \frac{\delta_{\mathrm{p}}^{*}}{\delta_{0}^{*}}=10^{\left[-0.0432 \alpha+0.00113 \alpha^{2}\right]} \\
& \frac{\theta_{\mathrm{p}}}{\theta_{0}}=10^{\left[-0.04508 \alpha+0.000873 \alpha^{2}\right]}
\end{aligned}
$$

The suction side boundary layers expressions for non-zero angle of attack and untripped condition are given by

$$
\begin{aligned}
& \frac{\delta_{\mathrm{s}}}{\delta_{0}}=10^{[0.03114 \alpha]} \text { for } 0 \leq \alpha \leq 7.5 \\
& 0.0303 .10^{[0.2336 \alpha]} \text { for } 7.5 \leq \alpha \leq 12.5 \\
& 12.10^{[0.258 \alpha]} \text { for } 12.5 \leq \alpha \leq 25 \\
& \frac{\delta_{\mathrm{s}}^{*}}{\delta_{0}^{*}}=10^{[0.0679 \alpha]} \text { for } 0 \leq \alpha \leq 7.5 \\
& 0.0162 .10^{[0.3066 \alpha]} \text { for } 7.5 \leq \alpha \leq 12.5 \\
& 52.42 .10^{[0.258 \alpha]} \text { for } 12.5 \leq \alpha \leq 25 \\
& \frac{\theta_{\mathrm{s}}}{\theta_{0}}=10^{[0.0559 \alpha]} \text { for } 0 \leq \alpha \leq 7.5 \\
& 0.0633 .10^{[0.2157 \alpha]} \text { for } 7.5 \leq \alpha \leq 12.5
\end{aligned}
$$




$$
14.977 .10^{[0.258 \alpha]} \text { for } 12.5 \leq \alpha \leq 25
$$

As mentioned in section 2.1, the spectral amplitude functions $\mathrm{K} 1$ and $\mathrm{K} 2$ and adjustment function $\Delta \mathrm{K} 1$ are expressed in terms of chord wise Reynolds number, and Reynolds number dependent on the pressure side displacement thickness; angle definitions are dependent on convective Mach number, $M_{c}$. The Strouhal number dependent on angle of attack is given by Eq. 23 to Eq. 25

$$
\begin{aligned}
& \mathrm{St}_{2}=\mathrm{St}_{1} \text { for } \alpha<1.33 \\
& \mathrm{St}_{2}=\mathrm{St}_{1} \times 10^{0.0054(\alpha-1.33)^{2}} \text { for } 1.33<\alpha<12.5 \\
& \mathrm{St}_{2}=4.72 \times \mathrm{St} 1 \text { for } \alpha>12.5
\end{aligned}
$$

Interpolated values at each point on the aerofoil surface are obtained by comparing with the reference Reynolds number and corrected angle of attack. The reference Reynolds number according BPM model is given by Eq. 26 and Eq. 27

$$
\begin{aligned}
& \mathrm{Rc}_{0}=10^{(0.215 \alpha+4.978)} \text { for } \alpha<3 \mathrm{deg} \\
& \mathrm{Rc}_{0}=10^{(0.12 \alpha+5.263)} \text { for } \alpha>3 \mathrm{deg}
\end{aligned}
$$

The ratio of boundary layer thickness to boundary layer displacement thickness, $R$ $=\frac{\delta}{\delta^{*}}$, is utilized to calculate the boundary layer displacement thickness at each blade segment iteratively for all the azimuthal and observer positions for both suction and pressure sides of aerofoil. The output from the boundary layer and displacement thickness is required to evaluate the Strouhal number as well as the sound pressure level from pressure, suction and flow separation noise components. The peak Strouhal number of 0.1 for the spectral functions $A$ and B is found according to [6], for which sound levels reach maximum value. The interpolation factors were used to scale the spectral functions at each point along the blade span segment length and also to check if Reynolds number at a span station is higher than critical or reference Reynolds number criterion.

\section{Results \& discussion}

\subsection{Sound power level}

From Table 1, it can be seen that for a three blade rotor, the maximum sound power level (SPL) of $97 \mathrm{dBA}$ is found between $200 \mathrm{~Hz}$ and $1 \mathrm{kHz}$ in case of BPM model, while for Grosveld model too, the maximum SPL of $91.6 \mathrm{dBA}$ is found. In case of Lowson, the peak is found at $200 \mathrm{~Hz}$ and equal to $95.1 \mathrm{dBA}$. This difference suggests that Grosveld model under-predicts trailing edge noise level compared to BPM and Lowson methods. For a two blade rotor, the maximum SPL of $92 \mathrm{dBA}$ is obtained using BPM model, while for Grosveld and Lowson models, it is found to be $86.4 \mathrm{dBA}$ and 91.9 $\mathrm{dBA}$ respectively. Obviously, it can be inferred that the maximum difference in sound levels between three blade and two blade rotor is in order of $5 \mathrm{dBA}$ between $63 \mathrm{~Hz}$ and $8 \mathrm{kHz}$ for all three methods. Since the human perception is sensitive to certain band of frequencies, the A-weighted filter correction was used for SPL values of trailing edge noise dominant between $1 \mathrm{kHz}$ and $5 \mathrm{kHz}$. However, it is also known that wind turbine blades produce low frequency broadband noise during operation and tend to propagate 
Table 1 Comparison of change in computed sound power level, $L_{w A}$ for three and two blade rotors of a $2 \mathrm{MW}$ wind turbine rotor blades at $\mathrm{U}_{10}=10 \mathrm{~m} / \mathrm{s}$ using BPM, Grosveld and Lowson methods

\begin{tabular}{|c|c|c|c|c|c|c|c|c|c|c|}
\hline & \multicolumn{10}{|c|}{ Frequency $(\mathrm{Hz})$} \\
\hline & 63 & 100 & 200 & 400 & 800 & 1000 & 2000 & 4000 & 5000 & 8000 \\
\hline \multicolumn{11}{|l|}{$\overline{B P M}$} \\
\hline $\mathrm{SPL}[\mathrm{dBA}]_{3, \text { blade }}$ & 61.3 & 73.0 & 88.6 & 97.0 & 94.9 & 94.3 & 89.7 & 82.4 & 79.4 & 72.0 \\
\hline $\mathrm{SPL}[\mathrm{dBA}]_{2, \text { blade }}$ & 56.3 & 68.0 & 83.6 & 92.0 & 89.9 & 89.3 & 84.6 & 77.3 & 74.3 & 67.0 \\
\hline$\Delta \mathrm{dBA}$ & 5.0 & 5.0 & 4.9 & 5.0 & 5.0 & 5.0 & 5.1 & 5.1 & 5.1 & 5.1 \\
\hline \multicolumn{11}{|l|}{ Grosveld } \\
\hline $\mathrm{SPL}[\mathrm{dBA}]_{3, \text { blade }}$ & 77.2 & 84.4 & 90.2 & 91.6 & 89.2 & 87.8 & 81.7 & 74.0 & 71.0 & 64.3 \\
\hline $\mathrm{SPL}[\mathrm{dBA}]_{2, \text { blade }}$ & 72.9 & 79.4 & 85.0 & 86.4 & 84.1 & 82.6 & 76.6 & 68.9 & 65.9 & 59.2 \\
\hline$\Delta \mathrm{dBA}$ & 4.2 & 4.9 & 5.3 & 5.2 & 5.1 & 5.1 & 5.1 & 5.1 & 5.1 & 5.1 \\
\hline \multicolumn{11}{|l|}{ Lowson } \\
\hline $\mathrm{SPL}[\mathrm{dBA}]_{3, \text { blade }}$ & 83.2 & 90.3 & 95.1 & 94.5 & 89.8 & 87.6 & 79.3 & 69.6 & 66.0 & 57.9 \\
\hline $\mathrm{SPL}[\mathrm{dBA}]_{2, \text { blade }}$ & 81.8 & 88.7 & 93.0 & 91.9 & 87.0 & 84.8 & 76.6 & 66.8 & 63.2 & 55.2 \\
\hline$\Delta \mathrm{dBA}$ & 1.4 & 1.6 & 2.1 & 2.6 & 2.7 & 2.8 & 2.8 & 2.8 & 2.8 & 2.8 \\
\hline
\end{tabular}

larger distances than tonal or impulse noise sources [1, 10-12]. Since A-weighting filter underestimates low frequency noise levels, a G-weighting filter is recommended, which takes into account the infrasonic, i.e. $\mathrm{f}<20 \mathrm{~Hz}$, and low frequency noise components, i.e. $20 \mathrm{~Hz}<\mathrm{f}<200 \mathrm{~Hz}$.

Table 2 shows the comparison of local rotor solidity along the blade span for three blade and two blade rotor. The solidity factor is found to be high towards the inboard region where the chord length is widest while reducing towards outboard region due to decreasing chord length. Local solidity factor is hence a function of the chord length and blade segment radius at a given span section. This effect is continuous regardless of turbine size but dependent upon the operating speed of the turbine [10,23, 24]. The rotational speed of machine also affects the blade passing frequency while the number of blades affects swept area of rotor that comes in contact with prevailing wind. The slower running machines tend to possess high power density $\left(\mathrm{W} / \mathrm{m}^{2}\right)$ and produce more power compared to machines which rotate faster and are smaller in size. Further, large scale studies conducted by [10] have shown that perceived sound pressure levels vary with microphone placement indoor in houses with windows closed or open. Data for machines of different sizes ranging from $200 \mathrm{~kW}$ to $2.5 \mathrm{MW}$ were obtained and studied at different operating conditions. Their findings have revealed that for two blade rotor, the impulsive noise source dominates for downwind configuration with blade passage frequency (BPF) of $\sim 0.77 / 1.17 \mathrm{~Hz}$ for MOD- 1 with a nominal rating of 2 MW, while for upwind configuration, the blade passage frequency is $0.59 \mathrm{~Hz}$ at 17.5 RPM. For the present study, the blade passage frequencies for three blade and two

Table 2 Blade solidity factor along blade span

\begin{tabular}{|c|c|c|c|c|c|c|c|c|c|}
\hline \multirow{2}{*}{$\begin{array}{l}\text { \# of } \\
\text { blades }\end{array}$} & \multicolumn{9}{|l|}{$r / R$} \\
\hline & 0.03 & 0.06 & 0.09 & 0.12 & 0.15 & 0.32 & 0.41 & 0.67 & 0.95 \\
\hline 2 Blade & 0.57 & 0.32 & 0.26 & 0.22 & 0.19 & 0.08 & 0.05 & 0.02 & 0.01 \\
\hline 3 blade & 0.86 & 0.48 & 0.38 & 0.33 & 0.29 & 0.12 & 0.08 & 0.03 & 0.01 \\
\hline
\end{tabular}


blade machines are $0.85 \mathrm{~Hz}$ and $0.57 \mathrm{~Hz}$ respectively. The blade passing frequency for a rotor can be evaluated according to Eq. 28

$$
\mathrm{BPF}=\omega \mathrm{N} / 60
$$

Where $\omega$ is angular speed in RPM, and $\mathrm{N}$ is the number of blades. This suggests that rotational harmonics is a function of number of blades in a machine or its integral multiples, which produce strong impulses when rotor is mounted downwind direction of wind [10]. Radiated noise from trailing edge of blade surface is therefore sensitive to rotational harmonic noise components and subjected to short duration load fluctuations due to wind speed deficit when blade passes the aerodynamic wake of tower and leads to amplitude modulation of sound waves. The impulse noise produced is transient in nature with a phase change of $180^{\circ}$ when the blades move past the tower wake. The amplitude of impulse decays with time for low Mach number flows and is affected by the free stream wind velocity $[7,8,10]$. In the current study, the impulsive noise component is ignored as the turbine rotor is assumed to be upwind. The hub height or source of turbine is $80 \mathrm{~m}$ above ground, for which the rotor inflow velocity gradient is assumed due to wind shear across the rotor. Hence a wind shear correction has been added to the acoustic data obtained from numerical computations using each of the three models. All numerical computations have been carried out using MATLAB 2019b software. Figure 6(a) depicts the aerodynamic load over the blade section of finite length, L. This load typically acts along the quarter chord line where the aerodynamic centre is located. Figure $6(\mathrm{~b})$ illustrates the acoustic directivity pattern of trailing edge noise from an aerofoil that resembles cardioid. This shows that for low Mach number flows, the sound pressure level scales with fifth power of Mach number and exhibits dipole behaviour. The aerofoils are treated as point source in source region and blade as line source in near field. As mentioned in sections 2.1 to 2.3, the sound waves undergo convective amplification downstream of chord length due to edge scattering of turbulent boundary layer with aerofoil surface [12].

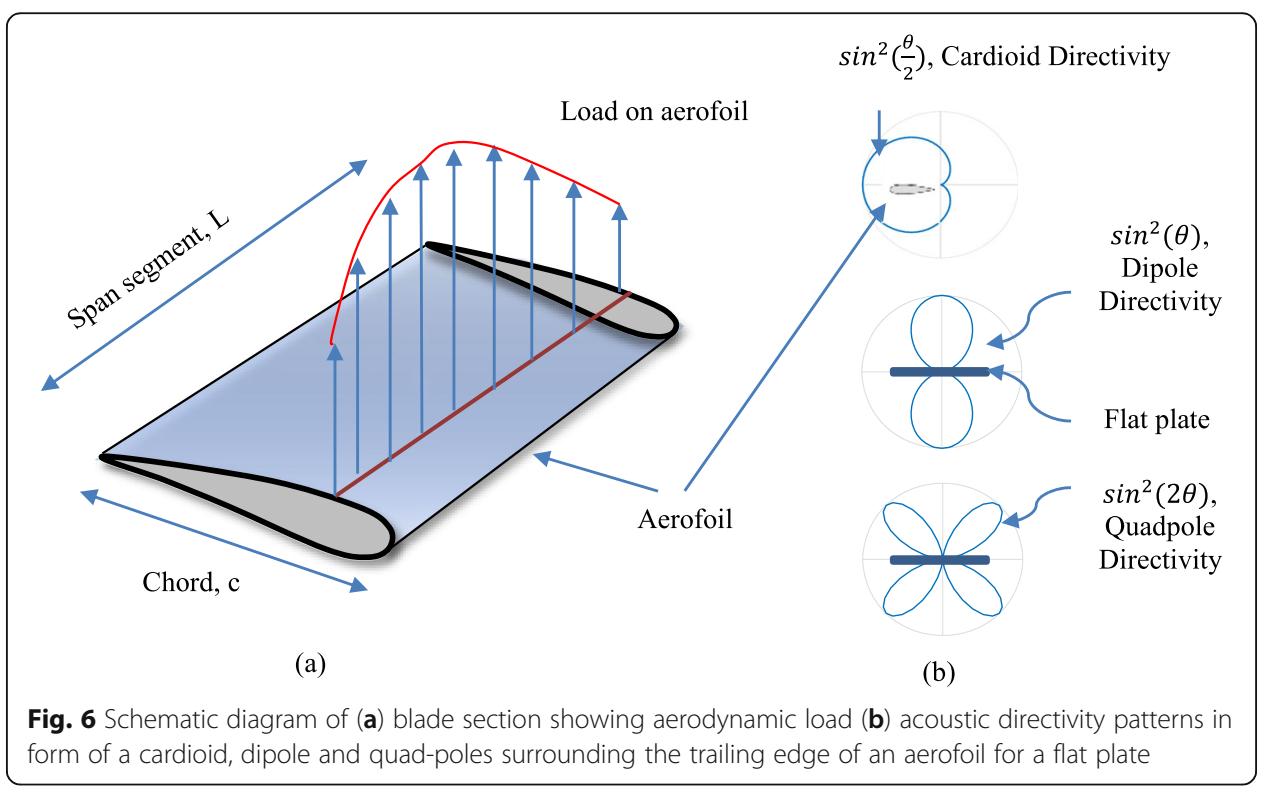


Also it can be noted that numerator in directivity function given by Eq. 7 shows a dipole like behaviour as shown in Fig. 6(b), when the sound pressure is scaled to sixth power of Mach number. This is due to compact nature of source when the wavelength of acoustic waves exceeds the characteristic dimension of source. In case of wind turbine, the noise is radiated in outward normal direction to chord length with distinct lobes on both pressure and suction sides of aerofoil and extends into upstream direction of chord length; however, for subsonic Mach number flows, the blade loading in rotor plane exhibits a cardioid pattern as shown in Fig. 6(b), [7, 10]. Further, the directivity pattern can also be seen as quad-pole in nature for volume sources and function of acoustic wave number $[18,19]$. For a wind turbine, unsteady aerodynamic flow over the blade produces lift and drag forces and undergoes dynamic stall during its operation due to flow separation occurring over blade surface [3]. Most of commercial large scale wind turbines operate at high Reynolds number and the turbulent boundary layer flow over blade causes stall separation to occur at high angle of attack, $\alpha>16^{\circ}$ and result in unsteady blade loading. It must be noted that the separation stall noise given by Eq. 3 according to BPM increases the amplitude of sound power level by $\sim 10 \mathrm{~dB}$ and is not accounted by Grosveld, Lowson methods [9].

From Fig. 7(a), it can be noted that for frequencies $\mathrm{f}<400 \mathrm{~Hz}$, the BPM model shows that two blade rotor produces higher noise level compared to rotor with 3 blades. However, for mid band to high frequencies between $250 \mathrm{~Hz}<\mathrm{f}<5 \mathrm{kHz}$, a difference of $\sim 5$ dBA can clearly be seen.

In Fig. 7(b), the Lowson model predicts a maximum SPL value of $95 \mathrm{dBA}$ at $200 \mathrm{~Hz}$ and shows a difference of 1.5dBA between two blade and three blade rotor for $63 \mathrm{~Hz}<$ $\mathrm{f}<8 \mathrm{kHz}$. In Fig. $7(\mathrm{c})$, the Grosveld model shows a similar trend with a difference of $~$ 4.8 dBA for the frequency range $100 \mathrm{~Hz}<\mathrm{f}<5 \mathrm{kHz}$. Although $2 \mathrm{~dB}$ increase in threshold sound level cannot be perceived highly in outdoor noisy environments such as open land, it can be regarded that human perception plays an important role in establishing threshold limits for noise measurements in urban or remote living conditions [1, 10]. Figure 8(a) to (c) shows the contour plot of sound power level, $\mathrm{L}_{\mathrm{w}}$ for hub height velocities up to $12 \mathrm{~m} / \mathrm{s}$ using each of the trailing edge noise models. Apparently at $1 \mathrm{kHz}$, the BPM model shows a peak in form of broad hump close to $1 \mathrm{kHz}$ due to the amplitude modulation from suction side of blade, while for Grosveld and Lowson models, it extends a little further towards the low frequency.

\subsection{Validation}

In this section, the computed sound power levels are validated using the experimental data of three blade GE 1.5sle turbine with a rotor diameter of $77 \mathrm{~m}$ at $10 \mathrm{~m} / \mathrm{s}$. From Fig. 9, it can be said that when $N=3$, the experimental values of GE 1.5sle rotor agree well with BPM model between $250 \mathrm{~Hz}$ and $8 \mathrm{kHz}$, however in the low frequency region, for $63 \mathrm{~Hz}<\mathrm{f}<200 \mathrm{~Hz}$, the Lowson model agrees well with experimental results of GE 15sle rotor, but the Grosveld model for trailing edge noise under-predicts the sound power levels compared to BPM and Lowson model. The Grosveld model shows a difference, $\triangle \mathrm{dBA}$ of $4-5 \mathrm{dBA}$ in case of two and three blade rotors, while $\triangle \mathrm{dBA}$ with respect to measured results of GE 1.5 sle shows up to $7 \mathrm{dBA}$ between $1 \mathrm{kHz}$ and $8 \mathrm{kHz}$. In Fig. 10, it is also evident that computed sound power level of turbulent inflow model 


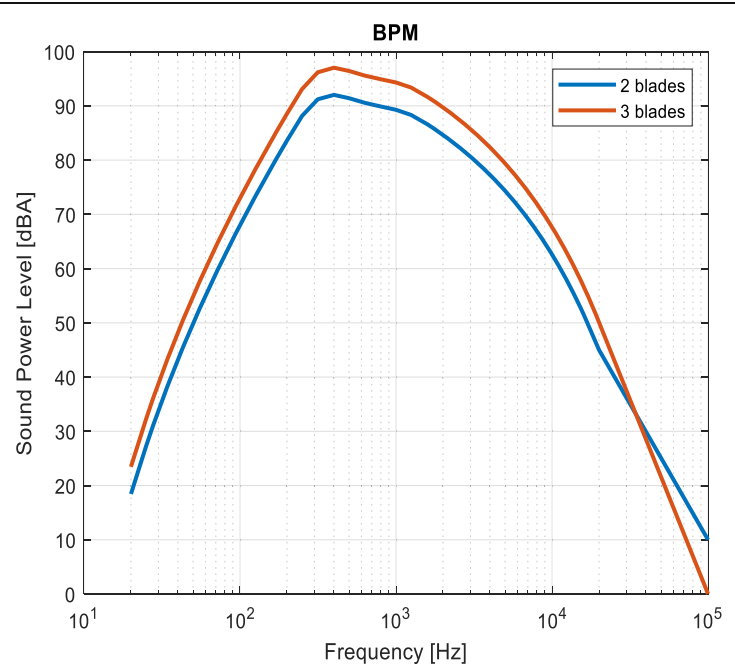

(a)

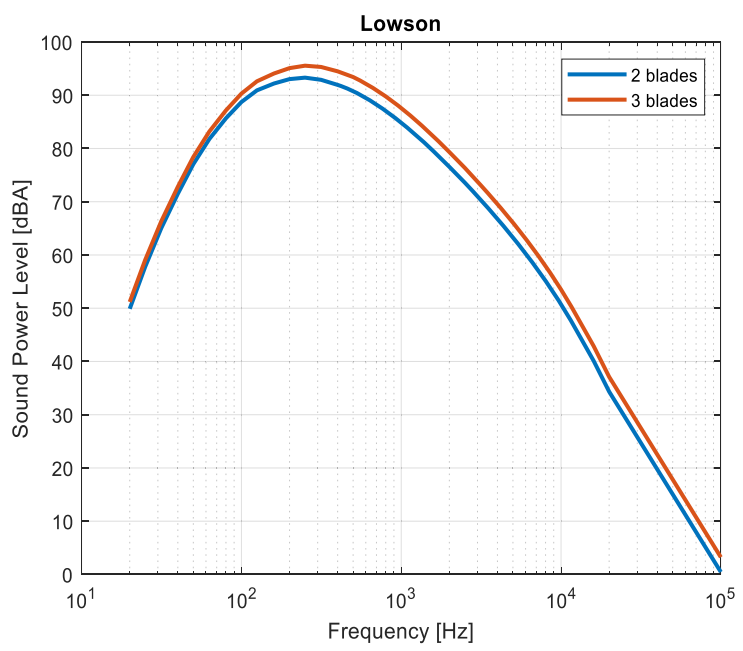

(b)

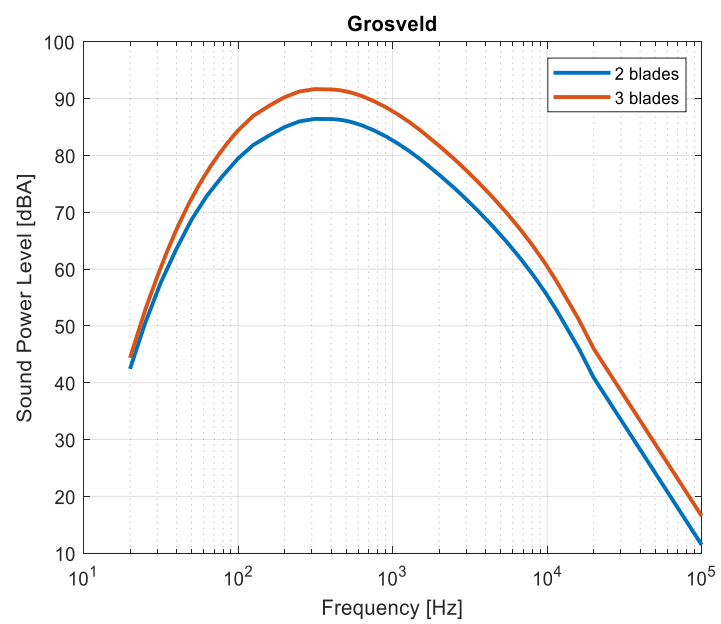

(c)

Fig. 7 Comparison of sound power level [dBA] for TBL-TEN source, using three trailing edge noise methods for a $2 \mathrm{MW}$ wind turbine rotor with two and three blades at $\mathrm{U}_{10}=10 \mathrm{~m} / \mathrm{s}$. a BPM (b) Lowson (c) Grosveld 

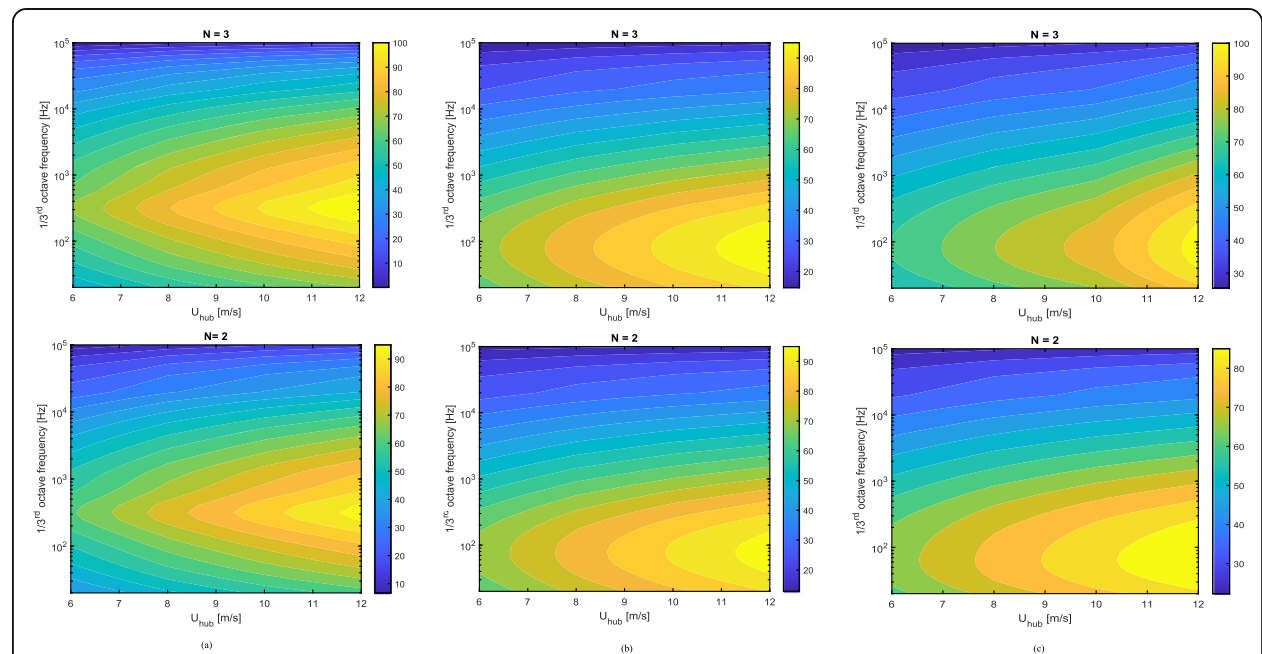

Fig. 8 Contour plot of Lw [dB] for three blade and two blade rotor using (a) BPM (b) Lowson (c) Grosveld trailing edge noise methods

by Moriarty P, Migliore P (2003) agrees well with respect to measured results of GE 1.5sle turbine with three blade rotor. The turbulent inflow noise for two and three blade rotor was computed at ambient turbulence intensity of $8 \%$ and length scale of $0.5 \mathrm{~m}$. This shows that computed results of sound power level for turbulent boundary layer trailing edge noise (TBL-TEN) vary with blade tip speed of machine as well as the

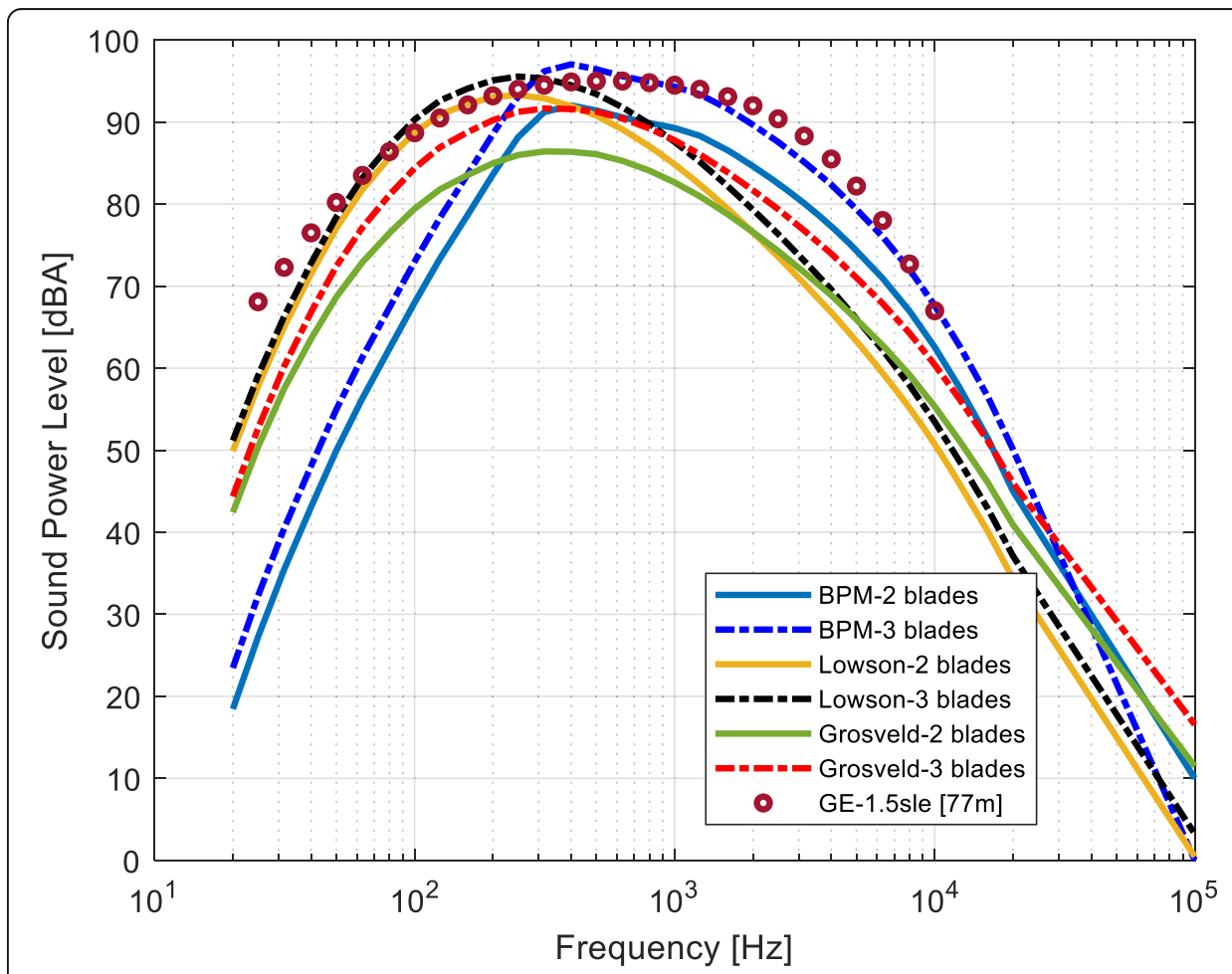

Fig. 9 Validation of computed sound power level from BPM, Grosveld and Lowson methods for 2 MW wind turbine with a rotor diameter of $76 \mathrm{~m}$ and three blades, with measured data of GE-1.5sle wind turbine with three blades and a rotor diameter of $77 \mathrm{~m}$ at wind speed, $U_{10}=10 \mathrm{~m} / \mathrm{s}$ 


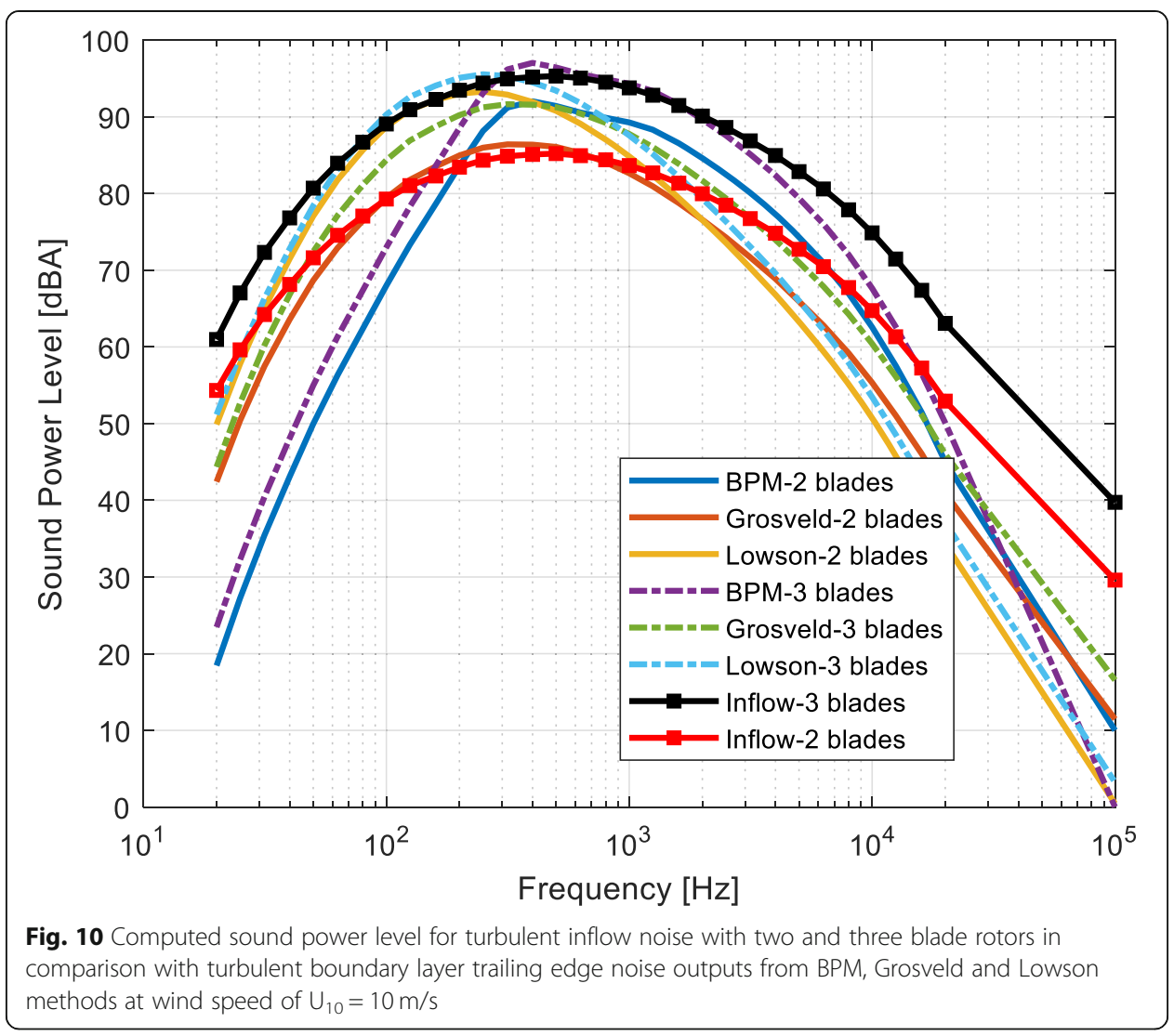

number of blades in rotor. From $400 \mathrm{~Hz}<\mathrm{f}<8 \mathrm{kHz}$, an uncertainty of 9-11dBA can be observed between the measured and computed result for three blade rotor using both Grosveld and Lowson methods. However for BPM method, the uncertainty of $<10$ $\mathrm{dBA}$ can be seen in case of three blade rotor, which suggests that BPM model predicts TBL-TEN fairly accurately than other two methods.

Finally, it can be noted that for constant turbine operating conditions, an uncertainty of $5.4 \%$ in sound power level is found for BPM model due to change in number of blades in rotor, but for Grosveld and Lowson model, it is $5.6 \%$ and 3\% respectively. This suggests that BPM model predicts the trailing edge noise levels fairly accurate between $400 \mathrm{~Hz}$ and $2 \mathrm{kHz}$ than the remaining two models.

\section{Concluding remarks}

- In the present work, the turbulent boundary layer trailing edge noise mechanisms from wind turbine blades according to models proposed from BPM, Grosveld and Lowson were evaluated. A computational study was conducted to verify the influence of number of blades on trailing edge noise output from the $2 \mathrm{MW}$ horizontal axis wind turbine with a blade length of $37 \mathrm{~m}$.

- The study revealed that for constant operating conditions of the turbine, the maximum prediction uncertainty in trailing edge noise levels increased as much as $\sim 5 \%$ when number of blades in rotor increased from two to three. A change of 
5dBA in sound power level was observed for BPM and Grosveld methods but Lowson method showed an increment of $2.5 \mathrm{dBA}$.

- This prediction uncertainty also varied according to $1 / 3$ rd octave band frequency. For low frequency region, $\mathrm{f}<100 \mathrm{~Hz}$, where inflow noise is dominant, the difference in trailing edge noise level is found to be very high for BPM model than Grosveld and Lowson models. It suggests that Lowson model is more suitable for predicting inflow noise level than BPM and Grosveld methods.

- In case of three blade rotor, an overall change of 9dBA-11dBA for trailing edge noise was found using Grosveld and Lowson methods while for BPM method it is $\sim 2 \mathrm{dBA}$ with respect to experimental data of GE 1.5sle turbine.

Abbreviations

BPM: Brookes, Pope and Marcolini; TBL-TEN: Turbulent boundary layer trailing edge noise; SPL: Sound power level; IEC: International Electro-technical Communications; ISO: International Standards Organization; CFD: Computational fluid dynamics; HH: Hub height; dBA: decibel A- weighted; BPF: Blade passing frequency

Acknowledgements

Authors would like to thank all reviewers who provided valuable feedback comments which helped to improve the quality of this work.

Authors' contributions

Sole contributors to this article. The authors read and approved the final manuscript.

\section{Funding}

No funding.

\section{Availability of data and materials}

Acoustic data is available upon request.

\section{Competing interests}

The authors have no competing interest.

\section{Author details}

${ }^{1}$ Department of Mechanical Engineering, Sreyas Institute of Engineering and Technology, Nagole, Hyderabad,

Telangana, India. ${ }^{2}$ Department of Aerospace Engineering, GITAM School of Technology, Patancheru, Telangana, India.

Received: 13 December 2019 Accepted: 22 April 2020

Published online: 29 June 2020

\section{References}

1. Bastasch M (2011) Summary of international wind turbine noise regulations. Technical report Renewable Northwest Project

2. Grosveld FW (1985) Prediction of broadband noise from horizontal axis wind turbines. J Propuls Power 1(4):292-299. https://doi.org/10.2514/3.22796

3. Hansen MOL (2008) Aerodynamics of wind turbines, 2nd edn. Earthscan Publishers, UK

4. Moriarty P, Migliore P (2003) Semi-empirical aero-acoustic noise prediction code for wind turbines. (TP-500-34478). NREL technical report. https://doi.org/10.2172/15006098

5. Schlinker RH, Amiet RK (1981) Helicopter rotor trailing edge noise. Presented at: 7th Aeronautics Conference, Palo Alto. https://doi.org/10.2514/6.1981-2001

6. Brooks TF, Pope DS, Marcolini MA (1989) Airfoil self-noise and prediction. (RP-1218). NASA technical report

7. Oerlemans S, Sijtsma P, López BM (2007) Location and quantification of noise sources on a wind turbine. J Sound Vib 229(4-5):869-883. https://doi.org/10.1016/j.jsv.2006.07.032

8. Oerlemans S (2011) Wind turbine noise: primary noise sources (NLR-TP-2011-066). NLR technical report

9. Zhu WJ, Heilskov N, Shen WZ, Sørensen JN (2005) Modeling of aerodynamically generated noise from wind turbines. Solar Energy Eng 127(4):517-528. https://doi.org/10.1115/1.2035700

10. Hubbard HH, Shepherd KP (1991) Aeroacoustics of large wind turbines. J Acoust Soc Am 89:2495. https://doi.org/10. $1121 / 1.401021$

11. Djikstra P (2015) Rotor noise and aero acoustic optimization of wind turbine aerofoils (master thesis). Technology University Delft, Delft

12. Doolan CJ, Moreau DJ, Brooks LA (2012) Wind turbine noise mechanisms and some concepts for its control. Acoustics Australia 40(1):7-13

13. Stalnov O, Chaitanya P, Joseph PF (2015) Prediction of broadband trailing edge noise based on Blake model and Amiet theory. 21st AIAA /CEAS Aero-acoustics Conference, Dallas, Texas. https://doi.org/10.2514/6.2015-2526

14. Sumesh CK, Sarvoththama Jothi TJ (2019) Aerodynamic noise characteristics of a thin airfoil with line distribution of holes adjacent to the trailing edge. International Journal of Aeroacoustics 18(4-5):496-516. https://doi.org/10.1177/ $1475472 \times 19860843$ 
15. Chaitanya P, Gill J, et al. (2015) Aerofoil geometry effects on turbulence interaction noise. 21st AIAA /CEAS Aeroacoustics Conference, Dallas, Texas. https://doi.org/10.2514/6.2015-2830

16. IEC 61400-11 Part 11 (2019) Acoustic noise measurement techniques report. Retrieved from https://webstore.iec.ch/

17. Zidan E, Elnady T, Elsabbagh A (2014) Comparison of sound power prediction models of wind turbines. Presented at: International Conference on Advances in Agricultural, Biological \& Environmental Sciences, Dubai

18. Fink MR (1979) Noise component method for airframe noise. J Aircr 16(10):659-665. https://doi.org/10.2514/3.58586

19. Lighthill MJ (1952) On sound generated aerodynamically. I. general theory. Proc Royal Soc London A 211:564-587

20. Croaker P, Mimani A, Doolan C, Kessissoglou N (2018) A computational flow induced noise and time reversal technique for analysing aero-acoustic sources. Journal of Acoustical Society of America 143(4):2301-2312. https://doi.org/10.1121/1. 5031113

21. Bailly C, Juve D (1998) Numerical solution of acoustic propagation problems using linearized Euler's equations. Presented at: 4th AIAA/CEAS Aeroacoustics Conference, Toulouse. https://doi.org/10.2514/6.1998-2267

22. XFOIL (2020) Subsonic airfoil development system Retrieved from https://web.mit.edu/drela/Public/web/xfoil/

23. Bhargava V, Samala R (2019) Effect of boundary layer and rotor speed on broadband noise from wind turbines. J Aerosp Technol Manag 11. https://doi.org/10.5028/jatm.v11.1045

24. Bhargava V, Samala R (2019) Acoustic emissions from wind turbine blades. J Aerospace Technol Management 11. https://doi.org/10.5028/jatm.v11.107

\section{Publisher's Note}

Springer Nature remains neutral with regard to jurisdictional claims in published maps and institutional affiliations.

Submit your manuscript to a SpringerOpen ${ }^{\circ}$ journal and benefit from:

- Convenient online submission

- Rigorous peer review

- Open access: articles freely available online

High visibility within the field

- Retaining the copyright to your article

Submit your next manuscript at $\boldsymbol{\nabla}$ springeropen.com 